\title{
Matemática e interdisciplinaridade: um estudo sobre os materiais didáticos
}

\author{
Dijalmary Matos Prates Chas ${ }^{1}$
}

\begin{abstract}
1 Especialista em Educação de Jovens e Adultos pela Faculdade São Braz, Especialista em Ensino da Matemática pela Universidade Estadual do Centro-Oeste e Graduada em Matemática pela Universidade Estadual do Centro-Oeste. Professora de Matemática e Física no Colégio Estadual Polivalente de Curitiba, Brasil.E-mail: dija_mary@hotmail.com
\end{abstract}

RESUMO: Uma das grandes dificuldades presentes no contexto escolar é a interdisciplinaridade no ensino e na aprendizagem da Matemática. De maneira geral, encontram-se certos obstáculos em relacionar seus conteúdos conceituais às suas aplicações e à integração da Matemática às outras ciências e disciplinas curriculares. Neste artigo, buscou-se analisar quatro livros didáticos do Ensino Fundamental, adotados no Colégio Estadual Polivalente de Curitiba $(P R)$, a fim de demonstrar se e como os livros associam à Matemática em outras disciplinas, e de que maneira tal interdisciplinaridade pode ser desenvolvida no ambiente escolar. Com relação às técnicas de investigação, foram analisados os conteúdos matemáticos presentes nos livros didáticos previamente selecionados e realizou-se entrevistas individuais semiestruturadas com os professores que utilizam tais materiais. Conclui-se que os livros didáticos permitem a associação de conteúdos matemáticos às outras disciplinas e que é necessário o desenvolvimento de um trabalho coletivo com o corpo docente para estimular o interesse, a curiosidade e a capacidade de resolução de problemas nos alunos.

Palavras-chave: Livro didático. Ensino. Multidisciplinaridade.

\section{Mathematics and interdisciplinarity: a study about teaching materials}

ABSTRACT: One of the great difficulties inside the school context is the interdisciplinarity in teaching and learning of mathematics. In general, there are some barriers on relating their conceptual content to their applications and also the integration of mathematics to others sciences and subjects. In this article, we have analyzed four didactic books of elementary and middle school adopted in "Colégio Estadual Polivalente de Curitiba" (PR), in order to demonstrate whether and how the books associate mathematics in other subjects and how this interdisciplinarity can be developed in school environment. In relation to investigation's techniques, we have analyzed the mathematical content present in previously selected didactic books and also the realization of semi-structured individuals interviews with teachers who uses those materials. We conclude that the didactic books allows the association of mathematical content to others disciplines and that there is a need of a development of a collective work with teaching staff to stimulate the interest, curiosity and the capacity of solving problems in the students.

Keywords: Didactic Book. Teaching. Multidisciplinary.

\section{INTRODUÇÃO}

O ensino da Matemática vem sendo aprimorado de acordo com as novas tendências da educação, de modo que não pode estar desvinculado das demais disciplinas e tampouco estar inerte quanto às questões que movimentam o meio escolar. A Mate- mática desempenha papel decisivo na formação de um cidadão crítico e transformador do meio em que vive, pois permite resolver problemas da vida cotidiana, apresenta aplicações no mundo do trabalho e funciona como instrumento essencial para a construção de conhecimentos em outras áreas curriculares. 
De acordo com os Parâmetros Curriculares Nacionais de Matemática (1998), uma das finalidades da Matemática no Ensino Fundamental é levar o aluno a estabelecer conexões entre temas matemáticos de diferentes campos e entre esses temas e conhecimentos de outras áreas curriculares. Propõe ainda, que o trabalho desenvolvido deve levar o aluno a valorizar a Matemática como um instrumento para compreender o mundo à sua volta - exercer a cidadania - e entendê-la como área do conhecimento que estimula o interesse, a curiosidade, 0 espírito de investigação e o desenvolvimento da capacidade para resolver problemas (BRASIL, 1998).

Ainda conforme os Parâmetros Curriculares Nacionais de Matemática (1998, p. 31), "a Matemática deverá ser vista pelo aluno como um conhecimento que pode favorecer o desenvolvimento do seu raciocínio, de sua capacidade expressiva, de sua sensibilidade estética e de sua imaginação".

No entanto, uma das grandes dificuldades presentes no contexto escolar refere-se ao ensino e à aprendizagem da Matemática relacionando seus conteúdos conceituais às suas aplicações, visando a integração da Matemática às outras ciências e disciplinas curriculares. A interdisciplinaridade é uma das ferramentas que objetiva minimizar a fragmentação comum ao processo de ensino aprendizagem, principalmente no Ensino Fundamental.

A interdisciplinaridade se faz presente e necessária para a compreensão de que os conhecimentos, fragmentados pela formatação curricular, são pontes que ligam os diversos ramos do saber científico numa infinidade de conexões entre os diversos saberes. Tal interdisciplinaridade melhora o entendimento dos conteúdos e busca novas descobertas, novos conhecimentos, que intermediarão outras conexões, dando suporte à curiosidade e perplexidade que os estudantes sentem diante da importância dada, por diferentes segmentos da sociedade, ao estudo de uma disciplina que aparentemente, na visão de muitos sujeitos, é desconexa da realidade cotidiana.

Sendo assim, neste artigo busca-se analisar quatro livros didáticos de disciplinas do Ensino Fundamental - História, Geografia, Português e Ciências -, adotados no Colégio Estadual Polivalente de Curitiba (PR), a fim de verificar se tais materiais expõem conceitos matemáticos que permitiriam o ensino interdisciplinar. O objetivo é demonstrar como outras áreas utilizam conteúdos matemáticos e que é possível aprender Matemática por meio de outras áreas, rompendo com os limites das disciplinas.

Assim, neste estudo, objetiva-se: a) analisar se é possível aprender Matemática por meio de outras áreas; b) verificar no livro didático de diversas disciplinas o estudo de conteúdos matemáticos, bem como a aplicação dos conceitos estudados na disciplina; e c) investigar como os livros didáticos de algumas disciplinas exploram os conhecimentos matemáticos.

\section{INTERDISCIPLINARIDADE NO ENSINO}

As discussões sobre interdisciplinaridade chegaram ao Brasil no final da década de 1960. De acordo com Ivani Fazenda (1991), a palavra interdisciplinaridade tornava-se de ordem a ser empreendida na educação, uma forma de modismo. A primeira produção significativa sobre o tema no Brasil é de Hilton Japiassú, que publica "Interdisciplinaridade e patologia do saber" em 1976.

Japiassú (1976) afirma que a interdisci- 
plinaridade se caracteriza pela intensidade de trocas entre os especialistas e pelo grau de integração das disciplinas no interior de um mesmo projeto de pesquisa. Ou seja, um processo dinâmico nas relações, visando um enriquecimento por ambas as partes, permitindo a abertura de espaços de diálogo entre as áreas do conhecimento, isto é, faz-se mister a intercomunicação entre as disciplinas, de modo que resulte uma modificação entre elas, através de diálogo compreensível, uma vez que a simples troca de informações entre organizações disciplinares não constitui um método interdisciplinar.

O ensino tradicional, em que os conteúdos são trabalhados de forma isolada com disciplinas que não dialogam, conduz a um processo educacional disciplinar desarticulado, que, em consequência, não permite ao educando seu desenvolvimento pleno. $O$ conhecimento precisa desenvolver as habilidades de forma integrada. Surge, então, no final do século passado, a interdisciplinaridade, a partir da necessidade de justificar a fragmentação causada por uma epistemologia de cunho positivista. As ciências foram divididas em muitas disciplinas e a interdisciplinaridade restabelecia, pelo menos, um diálogo entre elas. Considerada pela educação como uma relação interna da disciplina "matriz" e a disciplina "aplicada", a interdisciplinaridade passou a ser um termo aceito na educação por ser vista como uma forma de pensamento.

A proposta interdisciplinar visa romper com as barreiras entre as disciplinas e superar o compartimentalismo do pensar, na busca de uma aproximação do saber como elo entre todos os conhecimentos dos diversos campos. $\mathrm{Na}$ atual proposta para a educação, as escolas precisam quebrar pa-

Estação Científica (UNIFAP)

ISSN 2179-1902 radigmas e unir pontos benéficos do ensino tradicional à ideia da construção do saber a partir da integração das partes.

Segundo Paulo Freire (1987), a interdisciplinaridade é o processo metodológico de construção do conhecimento pelo sujeito com base em sua relação com o contexto, com a realidade e com sua cultura. Busca-se a interdisciplinaridade pela caracterização de dois movimentos dialéticos: a problematização da situação, pela qual se desvela a realidade, e a sistematização dos conhecimentos de forma integrada.

A psicopedagoga e professora de Língua Portuguesa, Lilian Aparecida Almeida Garrit dos Santos, afirma em seu artigo $^{1}$ que a globalização trouxe questionamentos como descentralização, flexibilidade dos programas escolares, valorização do conhecimento do educando, trabalho em equipe, democratização do saber, e principalmente, a preocupação em instruir cidadãos críticos e completos. Para isso ocorrer de maneira clara, a interdisciplinaridade, desenvolvida no século XXI, não pode ficar de fora.

No livro "Contribuições da Interdisciplinaridade: para a ciência, para a educação, para o trabalho sindical", Paulo Freire (1997), respondendo à Adriano Nogueira, assim se expressa, ao refletir acerca do seu entendimento em relação à interdisciplinaridade:

Pois veja, meu amigo, além da eficácia reflexiva destas etnias, temos aí mais uma outra evidência de que o Real é, enquanto Real, uma totalidade transdisciplinar. E só é apreendido em retotalizações. A inter(ou trans)disciplinaridade é demanda da Natureza e da Realidade do Mundo. É como se ela dissesse: 'vocês, Humanos, podem conhecer-

${ }^{1}$ Disponível em: http://www.educacaopublica.rj. gov.br/ jornal/materias/0440.html. Acesso em: 11 jun. 2015. 
me mas, para ajudá-los, eu vou logo dizendo que só me conhecerão com a condição de correlacionarem dialogicamente as múltiplas partes ou tendências que são necessárias a vocês'; A transdisciplinaridade, então, foi uma descoberta do Ser Humano, descoberta necessária. Necessária para quê? Para lidar com outra necessidade anteriormente descoberta: ela veio para lidar (retotalizando) com a necessidade da análise, que particulariza aspectos do Real (FREIRE, 1997, p. 23).

Assim, a compreensão da realidade, que é proporcionada pelas ciências particulares, possui, segundo Freire (1997), um grau de totalidade naquilo mesmo a que elas se propõem a conhecer, tornando-se eminentemente necessária a dialogicidade entre as diversas esferas (disciplinas) do saber.

A atividade interdisciplinar vem sendo considerada uma integração de conteúdos entre disciplinas do currículo escolar, sem diluir as disciplinas, que mantém sua individualidade, porém as integra a partir da compreensão das múltiplas causas ou fatores que intervêm sobre a realidade e trabaIha todas as linguagens necessárias para a constituição de conhecimentos, tornandoas comunicativas entre si (POMBO; GUIMARÃES; LEVY, 1993).

Quando se busca compreender o sentido da prática interdisciplinar é comum tentarmos uma inter-relação entre os conhecimentos. Assim, é importante explicitar as particularidades que envolvem as disciplinas e, portanto, seus conhecimentos específicos. Entretanto, constatamos que a construção do conhecimento só se constitui enquanto uma produção amplamente dialogada e articulada com as diversas áreas do saber. Segundo Piaget (1973), a interdisciplinaridade seria uma forma de se chegar à transdisciplinaridade, etapa que não fica- ria na interação e reciprocidade entre as ciências, mas alcançaria um estágio onde não haveria mais fronteiras entre as disciplinas.

Deste modo, a metodologia do trabalho interdisciplinar permitiria integrar os conteúdos, passar de uma concepção fragmentária para uma concepção unitária do conhecimento, superar a dicotomia entre ensino e pesquisa, considerando o estudo e a pesquisa a partir da contribuição das diversas ciências e ter o ensino-aprendiza-gem centrado numa visão de que se aprende ao longo de toda a vida.

A interdisciplinaridade empreende o envolvimento de especialistas, instrumentos como os materiais didáticos -, técnicas e análises diversas para a formação de uma atitude colaborativa dos sujeitos no ato de investigar e conhecer uma determinada temática.

Desse modo, a interdisciplinaridade adere às propostas de ensino com a ideia de relação, integração das disciplinas, ou seja, com a intenção de "aproximar" algo que, anteriormente, foi separado. O interesse sobre tal assunto vem se movimentando e documentos como os Parâmetros Curriculares Nacionais para o Ensino Médio (1999), o Programa Nacional do Livro Didático (2015) e os livros didáticos vêm se construindo e tomando essa nova proposta de reorganização do saber escolar, visando também sua prática. Desse modo, os guias didáticos pretendem colaborar para o momento de transição vivenciado, evidenciando o esforço das coleções em atender os princípios delineados pelos documentos oficiais, dentre eles, a interdisciplinaridade.

Em meio às exigências da Lei de Diretrizes e Bases (LDB), os Parâmetros Curriculares Nacionais para o Ensino Médio explicam 
que a tendência atual, em todos os níveis de ensino, é analisar a realidade segmentada, sem desenvolver a compreensão dos múltiplos conhecimentos que se interpenetram e conformam determinados fenômenos. Para essa visão segmentada contribui o enfoque meramente disciplinar que, na nova proposta de reforma curricular, pretendemos superá-lo pela perspectiva interdisciplinar e pela contextualização dos conhecimentos (BRASIL, 2000, p. 21).

\section{MATEMÁTICA E INTERDISCIPLINARIDADE}

Sabe-se que aprender Matemática consiste em trocar ideias e saberes, desenvolver as competências necessárias para o exercício da cidadania. Isso pressupõe que as pessoas desenvolvam sua capacidade de aprender, tendo como meios o domínio da leitura, da escrita e do conhecimento matemático, para que possam compreender o mundo e o ambiente em que vivem, atuando de forma crítica e participativa na sociedade.

A proposta para o ensino de Matemática contido nos Parâmetros Curriculares Nacionais vem ressaltar o caráter histórico, flexível e maleável do saber matemático, sugerindo a possibilidade da interdisciplinaridade. A integração curricular vem trazer uma aposta através da concepção do conhecimento matemático, construindo o debate a respeito da Matemática e da cidadania, ou seja, revelando a construção de estratégias, comprovação e justificativas de resultados, criatividade e iniciativa pessoal, o que levaria a habilidades de enfrentar desafios.

É, deste modo, a linguagem pela qual a ciência se comunica. D'Ambrosio (2001) afirma que,
O cotidiano está impregnado dos saberes e fazeres próprios da cultura. A todo instante, os indivíduos estão comparando, classificando, quantificando, medindo, explicando, generalizando, inferindo e, de algum modo, avaliando, usando os instrumentos materiais e intelectuais que são próprios à sua cultura (D'AMBROSIO, 2001, p. 22).

O autor relata uma série de trabalhos que nos mostram como a Matemática se apresenta no cotidiano das pessoas e, por consequência, é aplicada nas diferentes disciplinas. Mostra, assim, a importância de considerar o cotidiano dos discentes na aquisição do conhecimento matemático.

Segundo matéria de Luiz Carlos de Menezes na Revista Nova Escola ${ }^{2}$ :

Sem atividades desse tipo, crianças e jovens terão um menor domínio prático dessas linguagens. $E$ isso não se corrige simplesmente com uma proporção maior de aulas de Matemática, especialmente se elas se concentrarem na "gramática". O que fazer, então, para garantir aquelas práticas em toda a grade curricular? É preciso planejar, e o exercício de linguagens matemáticas nas várias disciplinas - mais do que possível, essencial - só ocorre se for previsto no projeto pedagógico, que não pode ser um documento de gaveta. E não fica prejudicado o ensino de Arte ou o de Geografia se os estudantes aprenderem a desenhar a cabeça de um adulto com $1 / 8$ da altura do corpo, a avaliar distâncias em perspectiva comparando triângulos, a reproduzir o trajeto da escola para a casa num guia com escala $1 / 10.000$, tomando 1 centímetro por 100 metros, ou a calcular o Índice de Desenvolvimento Humano (IDH) do município em que vivem (MENEZES, 2008).

Em outras palavras, a interdisciplinarida-

\footnotetext{
2 Disponível em: <http://revistaescola.abril.com. br/formacao/matematica-todas-disciplinas-4271 73.shtml>. Acesso em: 11 jun. 2015.
} 
de faz-se necessária para a compreensão dos conhecimentos, fragmentados pelas grades curriculares, e para a busca de novas descobertas que podem intermediar outras conexões. Especificamente no caso da Matemática, o conteúdo pode ser trabalhado em conjunto com outras disciplinas, estimulando a criatividade, ampliando o arsenal teórico utilizado e revigorando o estudo dos conteúdos.

Portanto, acompanha-se o posicionamento de Santomé (1996), de que a interdisciplinaridade implica em uma vontade e compromisso de elaborar um contexto mais geral, no qual cada uma das disciplinas em contato é modificada e passa a depender claramente uma das outras. Entre as diferentes matérias ocorrem intercâmbios mútuos e recíprocas integrações. Existe, desta forma, um equilíbrio de força nas relações estabelecidas.

Neste sentido, qualquer prática interdisciplinar acontece a partir de uma postura de expansão de campos e de abertura de fronteiras. No entanto, é necessário esclarecer, conforme explica Santomé (1996), que a interdisciplinaridade não implica somente criar espaços de encontros e de interseções entre áreas de conhecimento, mas constitui uma postura interdisciplinar que permite esse movimento de aproximação e transformação que vai além das disciplinas.

\section{METODOLOGIA}

Com base nos livros didáticos adotados pelo Colégio Estadual Polivalente de Curitiba (PR), por meio do Programa Institucional de Bolsa de Iniciação à Docência (PIBID), realizado em parceria com a Pontifícia Universidade Católica do Paraná (PUC-PR), rea- lizou-se uma análise de quatro livros didáticos adotados neste Colégio, a fim de verificar como tais materiais abordam os conteúdos matemáticos.

Os materiais didáticos analisados correspondem às disciplinas de História, Geografia, Português e Ciências, do $6^{\circ}$ ao $9^{\circ}$ ano de cada uma das quatro disciplinas. A análise consiste na investigação da abordagem dos conceitos matemáticos, bem como a aplicação de atividades contextualizadas da disciplina do referido material com a Matemática.

Os livros analisados são os seguintes:

1) História $\left(6^{\circ}\right.$ e $8^{\circ}$ ano): MOTOOKA, Débora Yumi; BARBOSA, Muryatan Santana. Para viver juntos: História. 3.ed. São Paulo: Edições SM, 2012.

2) Geografia ( $6^{\circ}$ e $7^{\circ}$ ano): VEDOVATE, Fernando Celo. Projeto Araribá: Geografia. 3 ed. São Paulo: Moderna, 2010.

3) Português ( $8^{\circ}$ e $9^{\circ}$ ano): TAVARES, Rosemeire Aparecida Alves; CONSELVAN, Tatiane Brugnerotto. Vontade de saber português. 1. ed. São Paulo: FTD, 2012.

4) Ciências ( $7^{\circ}$ e $9^{\circ}$ ano): BARROS, Carlos; PAULINO, Wilson. Ciências. 5 ed. São Paulo: Ática, 2012.

Em seguida, realizou-se entrevistas ${ }^{3}$ individuais semiestruturadas com professores destas e de outras disciplinas, como Inglês, Artes e Educação Física. Segundo Belei et al. (2008), a entrevista semiestruturada é aquela em que existe um direcionamento das perguntas por meio de um roteiro previamente elaborado, composto geralmente por questões abertas, o qual permite uma interação social entre entrevistado e entrevistador. Para Manzini (1990, p. 154), esse

\footnotetext{
${ }^{3}$ As entrevistas foram realizadas por e-mail ou pessoalmente, em junho de 2015. 
tipo de entrevista permite a ampliação dos questionamentos, pode fazer emergir informações de forma mais livre e as respostas não estão condicionadas a uma padronização de alternativas.

As entrevistas realizadas com os professores seguiram um roteiro de perguntas que objetivavam apreender suas informações e opiniões acerca da interdisciplinaridade e da sua utilização no ambiente escolar. Após a realização das entrevistas, realiz*ou-se um paralelo entre as opiniões coletadas e a análise dos livros didáticos. Em outras palavras, essa técnica de investigação buscou compreender se ocorre o resgate da Matemática como língua materna e seu papel na sociedade, e se, na opinião dos docentes, é possível aprender Matemática por meio das matérias que lecionam e com o auxílio dos materiais didáticos analisados aqui.

\section{ANÁLISE E DISCUSSÃO DOS RESULTADOS}

A Matemática está inserida em diversas áreas da vida cotidiana, desde situações simples e básicas, até as mais complexas e que requerem um conhecimento mais aprofundado. Ao verificar as disciplinas ensinadas durante a vida de estudos de uma determinada pessoa, do Ensino Básico até a conclusão do Ensino Médio, e até mesmo no Ensino Superior, nota-se que independente da disciplina, existe o envolvimento da Matemática em todas elas, o que faz com que essa interdisciplinaridade esteja cada vez mais presente, ressaltando a importância de se dominar tal disciplina para uma melhor compreensão de todas as áreas de estudos.

Nas análises realizadas dos livros e conversas com os professores, percebe-se a utilização e o aprofundamento dos conhecimentos matemáticos nas diversas disciplinas, como sintetizado a seguir.

Geografia: a) Medição de distâncias e ângulos; b) Cartografia (estudo dos mapas) para realizar projeções cartográficas; c) Análise de dados estatísticos de renda e condições de vida; d) Movimentos e dimensões da Terra.

História: a) Estudos sobre os diversos calendários, suas funções e como são utilizados; b) O tempo medido (contagem dos séculos, periodização da história, contagem do tempo, ordenação dos fatos).

Português: a) Classes de palavras e nos numerais; b) Ordinais, cardinais, multiplicativo e fracionário; c) Leitura de símbolos numéricos que aparecem nos textos (exemplo: \%); d) Trabalho com dados estatísticos, interpretando gráficos e tabelas; e) Produção de textos de ficção com base no gráfico de um saldo bancário pessoal ao longo do ano.

Ciências: a) Conversão de unidades de medida; b) Cálculos com aplicações de fórmulas matemáticas; c) Organização de tabelas e diagramas sobre processos naturais; d) Funções; e) Escalas e conversões entre escalas; f) Regra de três.

Artes: a) Obras de arte que constituem arranjos geométricos; b) Proporções nas artes plásticas; c) A rítmica na música; d) Desenhos em proporções reais utilizando recursos geométricos para representar perspectivas; e) Obras de arte utilizando as mais variadas formas geométricas; f) Abstrato Geométrico; g) Figuras planas (bidimensional); h) Figuras tridimensionais; i) Volume;

Educação Física: a) Registram desempenhos atléticos e dados ergométricos, cargas adequadas nos programas de treinamento 
físico; b) Índice de massa corpórea (IMC) e no tempo de chegada de corridas; c) Formas e projeções geométricas, pois para formatar áreas e espaços é necessário a presença da matemática; d) Aproveitamento de alguma equipe no campeonato, tais como: número de vitórias, número de empates e outros.

Inglês: a) Contagem; b) Horários; c) Unidades de medidas; d) Temperaturas; e) Numerais; f) Textos; g) Idades.

\subsection{Análise do livro de Ciências}

BARROS, Carlos; PAULINO, Wilson. Ciências. 5 ed. São Paulo: Ática, 2012.

$9^{\circ}$ ano: Neste livro são abordados os conceitos básicos de Física e Química, e, consequentemente, encontra-se muitos conteúdos de Matemática. São comuns os conceitos de massa e medidas, como nas páginas 19, 20, 21 e 44, temperaturas como na página 124, movimento, os exemplos são encontrados nas páginas 42 e 43, além de exercícios integrando o conhecimento onde são necessários conhecimentos matemáticos, observados nas páginas 25 e 36.

Podemos encontrar funções (páginas 46, $47,51)$ em todas as fórmulas da Física, como na fórmula que determina a posição em função do tempo (página 53). No conceito de densidade (página 32), visualiza-se novamente o conceito de função e também de volume na página 83. A regra de três está presente na conversão de temperaturas para diferentes escalas (página 124) e a interpretação de dados estatísticos (página 132 e 143). As notações científicas, que são potências de base dez, são usadas em Física e em Química para cálculos com números muito grandes ou muito pequenos, como evidenciado na página 154.

$7^{\circ}$ ano: Esse livro trabalha com os Seres Vivos e apresenta vários conceitos matemáticos, principalmente em datas, massas e comprimentos dos animais estudados (página 10). Percebe-se também informações da escala de ampliação de imagens, como na página 11. A escala de ampliação aparece na legenda de imagens microscópicas de bactérias, protozoários, entre outros seres vivos muito pequenos que só podem ser observados e estudados através de imagens de microscópios, presentes nas páginas 12 , 19 e 23.

É frequente encontrar informações como massa e comprimento ao lado das fotos dos animais de determinadas espécies, como observado nas páginas 49 e 52 . Além de diversas informações históricas como datas na abertura de alguns capítulos (página 37).

\subsection{Análise do livro de Português}

TAVARES, Rosemeire Aparecida Alves; CONSELVAN, Tatiane Brugnerotto. Vontade de saber português. 1. ed. São Paulo: FTD, 2012.

$8^{\circ}$ ano: Muitos consideram o estudo da Língua Portuguesa como a outra face da moeda Matemática, e geralmente quem gosta de uma dessas matérias, não se "dá bem" ou prefere evitar a outra, afirmação essa, dada pelos próprios alunos durante as aulas. Entretanto, a interdisciplinaridade une também disciplinas que aparentam ser tão opostas. Para sustentar tal afirmação, apresenta-se a análise do livro do $8^{\circ}$ ano e um exemplo bem claro aonde tais disciplinas se unem, como trabalham juntas e como a compreensão de ambas é de suma importância para resolução do exercício 
com dados estatísticos.

Além da importância para a interpretação de gráficos e tabelas para realização de enquetes e seminários (páginas 40, 178, 182, 203 e 204), por meio de infográficos e um gráfico de pizza, os exercícios abordam as relações de deslocamento com transporte público, carro e bicicleta. Através das informações dadas ao estudante, após analisar seus números e dados estatísticos, pode-se chegar a conclusões e com isso responder as questões do problema e também construir textos a partir de suas conclusões.

$6^{\circ}$ ano: Neste livro, a Matemática é encontrada em vários conteúdos: nas classes de palavras "Numeral", como na página 132, na classificação dos numerais: ordinais, cardinais, multiplicativo e fracionário (páginas 129 até 134), e escrita de números por extenso, como na página 131.

Portanto, mesmo em disciplinas aparentemente tão distantes, percebe-se que a interdisciplinaridade da Matemática com as demais disciplinas sempre existirá e por isso, acredita-se que o conhecimento básico da Matemática pode facilitar os estudos em qualquer área.

\subsection{Análise do livro de História}

MOTOOKA, Débora Yumi; BARBOSA, Muryatan Santana. Para viver juntos: História. 3.ed. São Paulo: Edições SM, 2012.

8 ano: Ao realizar a análise encontrouse nas páginas 85,257 e 291, por exemplo, mapas e gráficos que são recursos que professores de Matemática podem utilizar para uma introdução ao plano cartesiano. Nos mapas: norte, sul, leste e oeste podem ser relacionados aos eixos $(x, y)$ e nos gráficos a relação entre duas escalas, quando o gráfi- co é crescente e decrescente, para que quando o aluno for trabalhar com estes gráficos, mapas e tabelas em Geografia já tenha os conhecimentos necessários para interpretação, discussões e análises.

$\mathrm{Na}$ página 257 encontrou-se na tabela "Estabelecimentos industriais por região", e os conteúdos matemáticos abordados nos temas: Porcentagem, estatística básica com diversas operações matemáticas e construções de gráficos.

A linha do tempo é trabalhada na página 65 e faz uma relação simples e ilustrativa da reta numérica, operações de adição e subtração e a ideia de infinito. Os numerais romanos também são utilizados.

$6^{\circ}$ ano: No livro do $6^{\circ}$ ano é possível verificar vários conteúdos matemáticos, como a contagem dos séculos, contagem do tempo, ordenação de fatos e periodização da História, nas páginas 14 e 15 . Leitura de uma linha do tempo, relação de tempo entre acontecimentos, nas páginas 18, 30, 31, 43, 47, 77 e outras. Análise de tabelas, páginas 178 e 179. Vemos o quanto é importante a aplicação dos conteúdos matemáticos na disciplina de História, principalmente no $6^{\circ}$ ano, onde a utilização da Matemática vai além de gráficos e tabelas.

\subsection{Análise do livro de Geografia}

VEDOVATE, Fernando Celo. Projeto Araribá: Geografia. 3 ed. São Paulo: Moderna, 2010.

$6^{\circ}$ ano: $\mathrm{Na}$ análise sobre a viabilidade do estudo matemático dentro da Geografia, encontrou-se as tabelas, gráficos, porcentagem e cálculos com operações matemáticas, havendo uma conexão entre as disciplinas, que cooperam mutuamente para a evolução da educação.

O livro de Geografia "Projeto Araribá" 
aborda a Matemática ao citar vários temas da Geografia que envolve os conceitos matemáticos como ferramenta para a compreensão da Geografia. Na página 44 observouse o uso da Matemática básica para cálculo de fusos horários. Pode-se citar também a página 59 que apresenta a proposta de exercícios que tem como pré-requisito saber analisar tabelas, que por sua vez é um conteúdo matemático. Nesse contexto, podese ressaltar as páginas 136 e 137, que apresentam o conteúdo de Escalas gráficas. Nesse tema a presença da Matemática é nítida, pois sem ela não haveria como representar grandes distâncias em pequenos espaços.

Já nas páginas 184 e 185 é ressaltado o conteúdo de representações gráficas, que requer conhecimentos matemáticos, como a análise de tabela para construção de gráficos, porcentagem e operações básicas.

70 ano: Nas páginas 38, 58 e 79 aparecem assuntos como Aspectos Demográficos do Brasil: densidade, população relativa, PIB, área, população, que podem ser relacionados à conjun-tos, divisões, adições, relações entre duas variáveis, frações, proporções, entre outras.

\subsection{A interdisciplinaridade na opinião dos professores}

Após a análise dos livros didáticos, diversos professores de disciplinas como Inglês, Artes e Educação Física foram entrevistados a fim de que se pudesse entender, de maneira mais efetiva e prática, como a Matemática pode ser compreendida por meio de outras disciplinas.

Para a professora de Geografia, Ivanete Galter, a disciplina está intimamente ligada à Matemática, conforme depoimento abai- xo:

É utilizada para o desenvolvimento de vários conteúdos, por exemplo, no cálculo de escalas, para determinar densidades demográficas de lugares, saber a diferença de fusos horários, no conteúdo População onde são necessários vários cálculos sobre taxas de natalidade, mortalidade, crescimento vegetativo, entre outros. Diante desta necessidade, fica nítido que o aprendizado da matemática afeta também o aprendizado da geografia e o trabalho em conjunto professor de matemática $x$ professor de geografia contribuiria de forma significativa no trabalho com os alunos, que eles não teriam tanta dificuldade na resolução dos exercícios e trabalhariam de forma prática os conteúdos estudados em matemática.

Após a análise explicativa e a opinião da professora, pode-se concluir que a Matemática está intrinsecamente ligada à Geografia, tendo em vista que a Geografia faz uso de cálculos, operações básicas, análise de gráficos e tabelas para uma melhor compreensão de determinados temas de estudos da matéria.

Na disciplina de Inglês, a professora Regina Ribeiro Lima relatou que o livro adotado pelo estado, não aborda nada de Matemática, em nenhum dos anos, nem mesmo os numerais. Ela trabalha os números, escrita e leitura, além de contas usando as quatro operações onde os resultados devem ser apresentados em inglês, e os textos, que utilizam o número nas suas diversas formas, medidas, horários, etc. A professora, para tanto, utiliza outros livros e passa atividades para os alunos.

Já a professora de Educação Física, Mary Matos Prates relatou que em vários momentos utiliza os conteúdos de Matemática em suas aulas: 
Utilizamos a Matemática na elaboração e acompanhamentos de campeonatos e jogos do Colégio e nas formas de pontuação de diferentes modalidades. No atletismo trabalhamos com a matemática em provas de salto em distância, triplo e altura - quando realizamos medidas, estudamos records, ângulos dos movimentos realizados; em provas de arremesso de peso, lançamento de disco e dardo também são utilizados ângulos e medidas; nas provas de pista (corridas): velocidade, distâncias, como funciona o centro de gravidade na largada, na saída baixa ângulo das pernas; estabelecer relações entre o tamanho da pista $(400 \mathrm{~m})$, calculando número de voltas numa prova de 1500, de 3000 metros. Em frequência cardíaca: Aferir batimentos no punho antes de qualquer atividade, marca 15s, o valor neste tempo multiplica por 4, normal dos batimentos antes de qualquer atividade é de 60 a 80 bpm (batimentos por minuto), faz qualquer movimento, polichinelo, correr no lugar, tira frequência novamente. Em jogos de Xadrez, onde é necessário que os jogadores trabalhem com estratégias, raciocínios, atenção, resolução de problemas. Nas séries iniciais é trabalhado as medidas na quadra: distância do chão para a tabela, para a rede de vôlei, etc. Nos cuidados com a alimentação, calculando as quantidades de calorias. Enfim, os alunos participam do esporte Orientação $e$ necessitam de conhecimentos de diversas áreas, especificando a Matemática, poderíamos citar: uso da bússola, leitura de mapas, uso de réguas e esquadros, cálculo de velocidade, uso de escalas, etc.

Em Artes, a professora Eliane Cardoso Boff relatou que a interdisciplinaridade com a Matemática é fundamental e necessária. Nas artes visuais, na pintura, na escultura e na arquitetura é necessário que o aluno tenha conhecimento de geometria e saiba fazer uso de instrumentos como esquadros, transferidores e compasso. Ela ainda expressou as dificuldades no desenvolvimento desses conteúdos devido à falta de habili- dade e até mesmo de conhecimento dos alunos no manuseio de instrumentos importantes, como o transferidor e o compasso.

O que se percebe é que depois que a disciplina de desenho geométrico, deixou de integrar a grade curricular e diretrizes curriculares a dificuldade no uso desses instrumentos ficou bastante acentuada e para trabalhar com esses conteúdos em Artes, necessita-se primeiro fazer algumas aulas para trabalhar o uso desses materiais e leitura dos instrumentos.

Ainda na disciplina de Artes, o desenvolvimento de algumas percepções nos alunos, como sensibilidade, apreciação estética e imaginação depende da interação entre Matemática e Artes. O estudo do espaço e da forma também estabelece conexões de obras de arte, pinturas, desenhos, esculturas e artesanato com a Matemática.

Atividades de Matemática com Artes contribuem para o desenvolvimento do raciocínio lógico-crítico e da sensibilidade, por meio dos alunos. Alguns conteúdos citados pela professora que fazem parte do seu planejamento são: Perspectiva, Proporção, Abstrato Geométrico, Figuras planas (bidimensional), Figuras tridimensionais, Volume, ente outros.

A professora de Geografia, Ivanete Galter acredita que o trabalho interdisciplinar ajuda muito na compreensão dos conteúdos, "pois os alunos veem significado no que estão estudando e ficam mais motivados $e$ interessados durante as aulas, comentando em sala que estão estudando também em outra disciplina".

Como a equipe trabalha em conjunto, as professoras fazem adaptações em seus planejamentos para trabalharem em paralelo alguns conteúdos, como a parte de escala e 
ângulos. Isso, de acordo com as professoras, facilita a aprendizagem e diminui as dificuldades dos alunos na compreensão dos conteúdos e na resolução das atividades, além de incentivar os alunos na apropriação do conteúdo, uma vez que os mesmos estarão aplicando na prática e em exercícios, os diversos conteúdos estudados em Matemática, utilizados em outras áreas.

Ao finalizar a análise dos livros didáticos e conversar com os professores das disciplinas, percebe-se que o ensino-aprendizado da Matemática também é possível por meio de outras áreas, tornando a aprendizagem mais significativa.

\section{CONCLUSÃO}

A interdisciplinaridade busca garantir a construção de um conhecimento globalizante que rompe os limites das disciplinas, que até então eram ditas incomunicáveis, permitindo assim, o fim da fragmentação do conhecimento, e proporcionando ao aluno uma aprendizagem mais significativa.

Após dialogarmos com os professores, conclui-se que o trabalho de parceria realizado entre os professores permite que a interdisciplinaridade funcione na escola, uma vez que os professores de diferentes áreas se comuniquem para que os conteúdos que serão utilizados nas diferentes séries sejam trabalhados em conjunto. Por exemplo, na parte sobre escalas, utilizado em Geografia no $6^{\circ}$ ano, é possível que o professor de Matemática trabalhe tal assunto antes com os alunos. Dentro da previsão curricular, os professores de ambas as disciplinas devem manter contato e antecipar o ensino de determinado conteúdo.

Segundo as Diretrizes Curriculares de Matemática do Paraná (2008, p. 27), anun- ciar a opção político-pedagógica por um currículo organizado em disciplinas que devem dialogar numa perspectiva interdisciplinar requer que se explicite qual concepção de interdisciplinaridade e de contextualização o fundamenta, pois, esses conceitos transitam pelas diferentes matrizes curriculares, das conservadoras às críticas, há muitas décadas.

Desta perspectiva, estabelecer relações interdisciplinares não é uma tarefa que se reduz a uma readequação metodológica curricular, como foi entendido, no passado, pela pedagogia dos projetos. A interdisciplinaridade é uma questão epistemológica e está na abordagem teórica e conceitual dada ao conteúdo em estudo, concretizandose na articulação das disciplinas cujos conceitos, teorias e práticas enriquecem a compreensão desse conteúdo.

Depois da análise dos livros didáticos e conversas com os professores, entende-se que devemos criar a oportunidade de relacionar as disciplinas, tendo em vista que os materiais didáticos, ao menos os aqui analisados, utilizam-se de diferentes conceitos e conteúdos matemáticos. É, portanto, necessário um trabalho em conjunto dos docentes de modo que os conteúdos sejam aproveitados para a construção das aulas que relacionem os conteúdos da Matemática com outras disciplinas, de modo a promover um ensino interativo e reflexivo.

Assim, percebe-se que quando os professores fazem um planejamento conjunto com o objetivo de facilitar a compreensão dos conceitos pelos alunos, estabelecendo relações entre as áreas, enriquecendo o conhecimento sobre a outra, o resultado é a construção de um saber mais complexo e menos fragmentado, que buscará trazer mais significado ao que o aluno aprende. 


\section{REFERÊNCIAS}

BRASIL. Ministério da Educação e do Desporto. Parâmetros Curriculares Nacionais Matemática 5a a 8a série. Brasília: MEC/SEF, 1998.

BRASIL. Secretaria de Educação Fundamental. Parâmetros Curriculares Nacionais para o Ensino Médio. Brasília: MEC/SEF, 2000.

$B E L E I, R$. A. et al. $O$ uso de entrevista, observação e videogravação em pesquisa qualitativa. Pelotas: Cadernos de Educação, n.30, p. 187-199, 2008.

D'AMBROSIO, U. Educação matemática: da teoria à prática. Campinas: Papirus, 2001.

FAZENDA, I. C. A. Interdisciplinaridade: um projeto em parceria. São Paulo: Loyola, 1991.

FREIRE, P. Pedagogia da autonomia: saberes necessários à prática educativa. 6. ed. Rio de Janeiro: Paz e Terra, 1997.

FREIRE, P. Pedagogia do oprimido. Rio de Janeiro: Paz e Terra, 1987.

JAPIASSÚ, H. Interdisciplinaridade e patologia do saber. Rio de Janeiro: Imago, 1976. MANZINI, E. J. A entrevista na pesquisa social. São Paulo: Didática, v. 26/27, p. 149158, 1990.

MENEZES, L. C. de. Matemática em todas as disciplinas. Revista Nova Escola, São Paulo, edição 215, set. 2008.

PARANÁ. Secretaria de Estado da Educação. Diretrizes Curriculares de Educação Física para os anos finais do Ensino Fundamental e para o Ensino Médio. Curitiba: SEED, 2008. Disponível em: <http://www.educado res.diaadia.pr.gov.br/arquivos/File/diretrize s/dc e_mat.pdf>. Acesso em: 12 jun. 2015. PIAGET, J. Problemas gerais da investigação interdisciplinar e mecanismos comuns. Lisboa: Bertrand, 1973.

POMBO, O.; GUIMARÃES, H.; LEVY, T. Inter- disciplinaridade: conceito, problema e perspectivas. In: POMBO, O.; GUIMARÃES, H.; LEVY, T. Interdisciplinaridade: reflexão e experiência. Lisboa: Texto, 1993.

SANTOMÉ, J. T. Globalização e interdisciplinaridade: o currículo integrado. Porto Alegre: Artes Médicas, 1996.

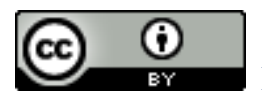

License information: This is an openaccess article distributed under the terms of the Creative Commons Attribution License, which permits unrestricted use, distribution, and reproduction in any medium, provided the original work is properly cited.

Artigo recebido em 28 de novembro de 2015

Avaliado em 06 de setembro de 2016.

Aceito em 13 de dezembro de 2016.

Publicado em 28 de março de 2017.

Como citar este artigo (ABNT):

CHAS, Dijalmary Matos Prates. Matemática e interdisciplinaridade: um estudo sobre os materiais didáticos. Estação Científica (UNIFAP), Macapá, v. 6, n. 3, p. 97-109, set./dez. 2016. 